\title{
Scour development around structures with non-uniform cylindrical geometries
}

\author{
N.S. Tavouktsoglou \\ University College London, London, UK
}

J.M. Harris

HR Wallingford, Wallingford, UK

R.R. Simons

University College London, London, UK

\author{
R.J.S. Whitehouse \\ HR Wallingford, Wallingford, UK
}

\begin{abstract}
Many offshore foundations are composed of non-uniform cylindrical geometries such as cones and different diameter composite cylinders. However, little is known about how these types of structure respond with regards to scour under the forcing of a unidirectional current. The present paper describes a series of laboratory experiments that have been performed to examine the effect that the geometry of a marine structure has on the evolution and equilibrium depth of scour under different hydrodynamic conditions. It was found that the hydrodynamic scour response of the non-uniform cylindrical structures is fundamentally different to that of a uniform cylinder.
\end{abstract}

\section{NOMENCLATURE}

D Diameter of a cylinder

$D_{\text {base }} \quad$ Diameter of the base of a non-uniform cylindrical structure

$\mathrm{D}_{\mathrm{eq}} \quad$ Equivalent pile diameter (according to Coleman, 2005)

Diameter of the upper shaft of a nonuniform cylindrical structure Mean sediment size of cohesioneless sediment

\section{$\mathrm{D}_{50}$}

$\mathrm{Fr}$

GBF

$\mathrm{h}$

$\mathrm{h}_{\text {base }}$

LDV

\section{$\operatorname{Re}$}

$\mathrm{S}$

$\mathrm{S}_{\mathrm{eq}}$

$\mathrm{t}$
Froude Number

Gravity Based Foundation

Flow depth

Height of the base of base of cylindrical based non-uniform cylindrical structure Laser Doppler Velocitymeter

Reynolds Number

Scour depth

Equilibrium scour depth time

depth averaged flow velocity

Critical depth averaged flow velocity

for bed sediment movement

Height of the foundation base taken as

the height from the bed up to the top of

the conical base

Distance from bed

Geometric standard deviation of non-

cohesive bed material

\section{INTRODUCTION}

Research into scour at offshore foundations has primarily focused on investigating the impact of different hydrodynamic conditions on scour around a monopile. Sumer and Fredsoe (2002) and Whitehouse (1998) provide comprehensive summaries of this research. While scour induced by a vertical cylinder has been extensively researched and provided an understanding of the key hydrodynamic processes influencing scour, often offshore foundations are used which are composed of more complex geometries such as cones and different diameter composite cylinders.

The complexity of local scour around nonuniform cylindrical structural geometries is explained by the strong three dimensional nature of the flow-structure interaction (i.e. horseshoe vortex generation, vortex shedding and downflow). Research in the flow-structure-sediment interaction for these types of structure is rather more recent than for monopiles, with relatively few studies being reported in literature, most of which having been conducted for bridge piers in rivers for composite cylindrical based structures. The effect of composite structural geometries was first investigated by Chabert and Engeldinger (1956) who examined the influence a larger diameter foundation footing has on scour; their results showed that the equilibrium scour depth was significantly reduced when the footing was below the original bed level. Khalfin et al. (1983) conducted a series of experiments around Gravity Based 
Foundations (GBFs) with cylindrical and conical bases and concluded that the scour processes between the two types of structure are fundamentally different. Specifically, the scour hole of the conical structure tended to be more elongated and scour deeper at the lee. Tsujimoto et al. (1987) conducted an experimental investigation on the effect non-cylindrical geometries have on scour and showed that scour was reduced for certain geometries. Jones et al. (1992) and Parola et al. (1996) conducted a series of experiments for piles installed on top of rectangular piles. They found that the equilibrium scour depth is strongly influenced by the emergent height of the base footing and the orientation of the rectangular footing. Melville and Raudkivi (1996) and Coleman (2005) investigated non-uniform cylinders; among their finding they showed that the ratio of $D_{\text {shaft }} /$ $\mathrm{D}_{\text {base }}$ and $\mathrm{h}_{\text {base }} / \mathrm{D}_{\text {base }}$ are controlling parameters for the equilibrium value of scour, in addition to the other parameters that effect monopiles. They also introduced the concept of non-dimensionalising scour using an equivalent diameter length scale which is calculated using an empirical relationship. Moreno et al. (2015) recently examined the effect that different structural parameters of cylindrical based structures have on the temporal evolution of scour and concluded that the rate of scour is associated with the progressive physical presence in the scour hole evolution of one, two, or three structural components of the non-uniform cylindrical pier.

The aim of the experimental test programme described here is to provide an insight to the influence of five different types of structures on the maximum potential scour depth (equilibrium scour depth assuming infinitely deep skirts) and also to understand the effect the water depth and particle mobility ratio $\left(U / U_{c}\right)$ has on the equilibrium scour and scour development. The outcomes of the tests can then be used for the estimation of the skirt depths required by GBFs.

\section{SCOUR TEST SET-UP}

In order to investigate the impact of non-uniform cylindrical foundation geometries on scour, a series of laboratory tests were conducted in the reversing current flume at University College London (UCL). The tests were designed in order to provide an initial insight to the scour processes involved, and enabling important features to be determined for further investigation at larger scale.

All test were conducted at a clear water scour regime under the forcing of a unidirectional current in order maintain a simple hydrodynamic regime for the tests. This also avoided the formation of bed features upstream of the test section which would lead to the general lowering of the initial bed and therefore complicate the determination of the scour depth.
Maintaining the same Froude number simultaneously with the $U / U_{c}$ in both prototype and model conditions was not possible, as this would lead to small model flow velocities which would require sediment particles with $\mathrm{D}_{50}<60 \mu \mathrm{m}$ (i.e. cohesive soils) in order achieve initiation of scour.

\subsection{Experimental Facilities}

In this experimental programme the tests were run in a flume $10 \mathrm{~m}$ long, $0.5 \mathrm{~m}$ deep and $0.3 \mathrm{~m}$ wide. A false bed was installed $0.1 \mathrm{~m}$ above the existing flume base with a $2 \mathrm{~m}$ recess at the middle which served as a sand pit where scour could develop freely (see figure 1). Test structures were placed in the centre of the flume at a distance approximately $4.5 \mathrm{~m}$ from the flume entrance. The flow velocity and water depth were controlled through an overhead tank and a weir gate which was located at the end of the flume.

\subsection{Instrumentation}

Two quantities were measured in these experiments:

- Equilibrium scour depth.

- The time development of the maximum scour depth

Scour depth was monitored using a camera which captured time-lapse images every $15 \mathrm{~s}$. The camera was installed at a steep angle adjacent to the glass sidewall of the flume. In order to measure the scour depth adjacent to the structure more clearly the buried portion of the foundation was marked at $5 \mathrm{~mm}$ intervals.

The total discharge of the flume was determined as a function the height of a weir and the discharge released by the overhead tank. In order to obtain the desired flow conditions full profile measurements of the flow were taken using a Laser Doppler Velocitymeter (LDV) at the centre of the test section. Once the desired flow conditions were obtained the experiments were then started. Non-dimensionalised profile measurements of the flow conditions used in these experiments are shown in figure 2 .

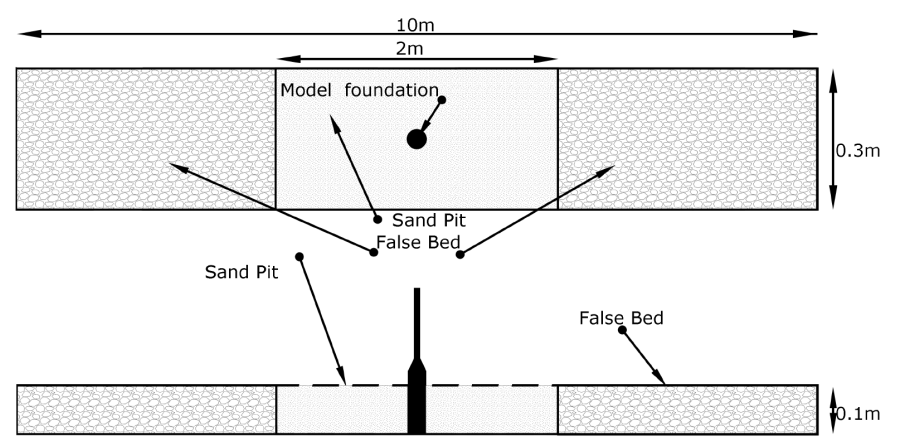

Figure 1: False bed set up (top: top-view; bottom: side-view). 
To avoid scaling issues due to the sediment size to pile diameter ratio, two sediment sizes were used in the experiments; these were selected in accordance with $\mathrm{D}_{\text {base }} / \mathrm{D}_{50}>50$ (Chiew, 1984). The flow depths were also selected such that the blockage effects could be neglected according to Whitehouse (1998).

In order to smooth the sand bed the structure was separated into two components. The base extended from the base of the flume up to the height of the false bed. This allowed the smoothing of the bed all the way to the edge of the structure toe. Once the bed was prepared the flow depth and velocity were increased to the desired level and the top part of the structure was then screwed onto the base, which allowed the immediate start of the experiment at the desired flow velocity, while causing the minimal disturbance of the bed.

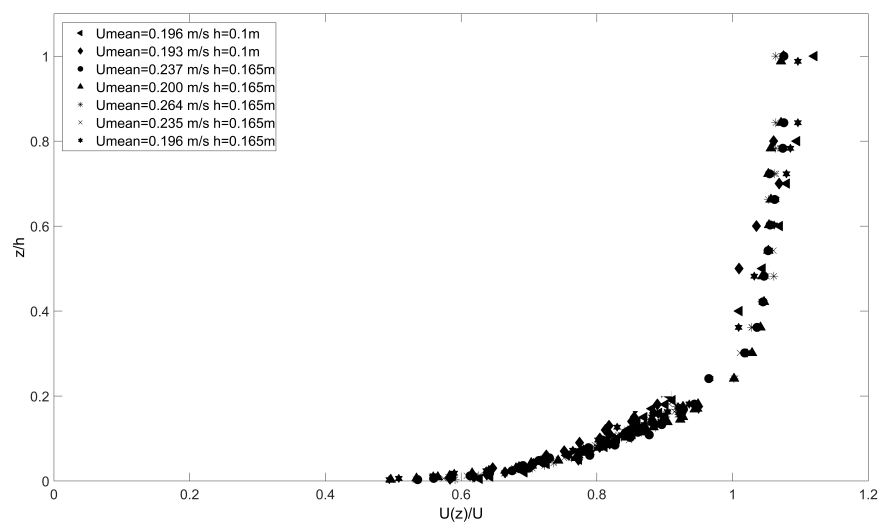

Figure 2: Non-dimensional flow profiles of tests

\subsection{Structure geometries}

In order to investigate the influence of structural geometries on the scour development six different structures were tested in this test programme. These include a truncated cylinder, a cylindrical base structure which for the purpose of the analysis that will be presented in the following sections is regarded as a structure with a side slope of $0^{\circ}$, three conical base structures of side slopes of $45^{\circ}, 60^{\circ}$ and $75^{\circ}$, and one monopile structure with diameter equal to the base diameter of the non-uniform cylindrical structures which is considered for the purpose of this paper a structure of $90^{\circ}$ (see figure 3 ).

The geometries presented in this section are representative of a range of structure types that have been used in the offshore wind industry. The latter five structures shown in figure 3 enabled the evaluation of the effect the side slope of a structure has on the scour processes, while the truncated cylinder allowed the evaluation of the effect the cylindrical component of the base of the structures has.

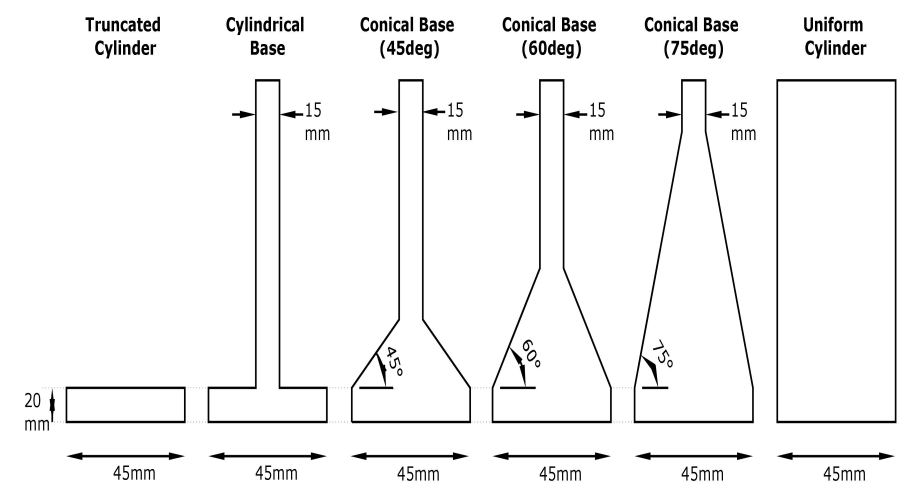

Figure 3: Structure geometries tested in the experimental programme.

\section{EXPERIMENTAL DATA AND RESULTS}

Table 1: Flow conditions and results

\begin{tabular}{|c|c|c|c|c|c|c|c|c|c|}
\hline $\begin{array}{c}\text { Exp. No. } \\
(-)\end{array}$ & $\begin{array}{c}\text { Structure Type } \\
(-)\end{array}$ & $\begin{array}{c}U \\
(\mathrm{~m} / \mathrm{s})\end{array}$ & $\begin{array}{c}\mathrm{h} \\
(\mathrm{m})\end{array}$ & $\begin{array}{c}\text { U/Uc } \\
(-)\end{array}$ & $\begin{array}{r}\mathrm{h} / \mathrm{D} \\
(-)\end{array}$ & $\begin{array}{l}\operatorname{Re} \\
(-)\end{array}$ & $\begin{array}{l}\mathrm{Fr} \\
(-)\end{array}$ & $\begin{array}{c}\text { S/Douter } \\
(-)\end{array}$ & $\begin{array}{c}\text { S/Deq } \\
(-)\end{array}$ \\
\hline 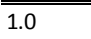 & Truncated & 0.20 & 0.165 & 0.73 & 3.67 & 8775 & 0.15 & 0.20 & 0.75 \\
\hline 1.1 & Cylindrical base & 0.20 & 0.165 & 0.73 & 3.67 & 8775 & 0.15 & .55 & 1.45 \\
\hline 1.2 & 45 deg conical base & 0.20 & 0.165 & 0.73 & 3.67 & 8775 & 0.15 & 0.80 & 1.90 \\
\hline 1.3 & 60 deg conical base & 0.20 & 0.165 & 0.73 & 3.67 & 8775 & 0.15 & 0.95 & 2.00 \\
\hline 1.4 & 75 deg conical base & 0.20 & 0.165 & 0.73 & 3.67 & 8775 & 0.15 & 1.13 & 2.30 \\
\hline 1.5 & Uniform cylinder & 0.20 & 0.165 & 0.73 & 3.67 & 8775 & 0.15 & 1.35 & 1.35 \\
\hline 1.6 & Truncated & 0.20 & 0.165 & 0.88 & 3.67 & 9000 & 0.16 & .73 & .75 \\
\hline 1.7 & Cylindrical base & 0.20 & 0.165 & 0.88 & 3.67 & 9000 & 0.16 & 1.16 & 3.05 \\
\hline 1.8 & 45 deg conical base & 0.20 & 0.165 & 0.88 & 3.67 & 9000 & 0.16 & 1.27 & 3.01 \\
\hline 1.9 & $60 \mathrm{deg}$ conical base & 0.20 & 0.165 & 0.88 & 3.67 & 9000 & 0.16 & 1.31 & 2.76 \\
\hline 1.10 & 75 deg conical base & 0.20 & 0.165 & 0.88 & 3.67 & 9000 & 0.16 & 1.38 & 2.80 \\
\hline 1.11 & Uniform cylinder & 0.20 & 0.165 & 0.88 & 3.67 & 9000 & 0.16 & .73 & 1.73 \\
\hline 1.12 & Truncated & 0.24 & 0.165 & 1.00 & 3.67 & 10665 & 0.19 & 1.02 & 3.83 \\
\hline 1.13 & Cylindrical base & 0.24 & 0.165 & 1.00 & 3.67 & 10665 & 0.19 & .49 & .93 \\
\hline 1.14 & 45 deg con & 0.24 & 0.165 & 1.00 & 3.67 & 10665 & 0.19 & 1.49 & 3.54 \\
\hline 1.15 & $60 \mathrm{deg}$ conical base & 0.24 & 0.165 & 1.00 & 3.67 & 10665 & 0.19 & 1.56 & 3.27 \\
\hline 1.16 & 75 deg conical base & 0.24 & 0.165 & 1.00 & 3.67 & 10665 & 0.19 & .64 & 3.35 \\
\hline 1.17 & Uniform cylinder & 0.24 & 0.165 & 1.00 & 3.67 & 10665 & 0.19 & 1.96 & 1.96 \\
\hline 1.18 & Truncated & 0.24 & 0.165 & 0.88 & 3.67 & 10575 & 0.18 & .76 & .83 \\
\hline 1.19 & Cylindrical base & 0.24 & 0.165 & 0.88 & 3.67 & 10575 & 0.18 & 1.18 & 3.11 \\
\hline 1.20 & 45 deg con & 0.24 & 0.165 & 0.88 & 3.67 & 10575 & 0.18 & 28 & 3.03 \\
\hline 1.21 & 60 deg conical base & 0.24 & 0.165 & 0.88 & 3.67 & 10575 & 0.18 & .32 & 2.78 \\
\hline 1.22 & $75 \mathrm{deg}$ & 0.24 & 0.165 & 0.88 & 3.67 & 10575 & 0.18 & 39 & 2.83 \\
\hline 1.23 & Uniform cylinder & 0.24 & 0.165 & 0.88 & 3.67 & 10575 & 0.18 & .76 & .76 \\
\hline 1.24 & Trunc & 0.26 & 0.165 & 0.99 & 3.67 & 11880 & 0.21 & .96 & 3.58 \\
\hline 1.25 & Cylindrical base & 0.26 & 0.165 & 0.99 & 3.67 & 11880 & 0.21 & 1.36 & 3.57 \\
\hline 1.26 & $45 \mathrm{deg}$ conical base & 0.26 & 0.165 & 0.99 & 3.67 & 11880 & 0.21 & 1.49 & 3.54 \\
\hline 1.27 & 60 deg conical base & 0.26 & 0.165 & 0.99 & 3.67 & 11880 & 0.21 & 1.53 & 3.23 \\
\hline 1.28 & 75 deg conical base & 0.26 & 0.165 & 0.99 & 3.67 & 11880 & 0.21 & 1.62 & 3.30 \\
\hline 1.29 & Uniform cylinder & 0.26 & 0.165 & 0.99 & 3.67 & 11880 & 0.21 & 1.91 & 1.91 \\
\hline 2.0 & Truncated & 0.20 & 0.1 & 0.90 & 2.22 & 8820 & 0.20 & 1.11 & 4.17 \\
\hline 2.1 & Cylindrical base & 0.20 & 0.1 & 0.90 & 2.22 & 8820 & 0.20 & 1.24 & 3.28 \\
\hline 2.2 & $45 \mathrm{deg}$ conical base & 0.20 & 0.1 & 0.90 & 2.22 & 8820 & 0.20 & 1.38 & 3.27 \\
\hline 2.3 & 60 deg conical base & 0.20 & 0.1 & 0.90 & 2.22 & 8820 & 0.20 & 1.49 & 3.13 \\
\hline 2.4 & 75 deg conical base & 0.20 & 0.1 & 0.90 & 2.22 & 8820 & 0.20 & 1.60 & 3.26 \\
\hline 2.5 & Uniform cylinder & 0.20 & 0.1 & 0.90 & 2.22 & 8820 & 0.20 & 1.70 & 1.70 \\
\hline 2.6 & Truncated & 0.20 & 0.1 & 0.75 & 2.22 & 8820 & 0.20 & 0.84 & 3.17 \\
\hline 2.7 & Cylindrical base & 0.20 & 0.1 & 0.75 & 2.22 & 8820 & 0.20 & 0.91 & 2.40 \\
\hline 2.8 & 45 deg conical base & 0.20 & 0.1 & 0.75 & 2.22 & 8820 & 0.20 & 1.02 & 2.43 \\
\hline 2.9 & 60 deg conical base & 0.20 & 0.1 & 0.75 & 2.22 & 8820 & 0.20 & 1.16 & 2.43 \\
\hline 2.10 & 75 deg conical base & 0.20 & 0.1 & 0.75 & 2.22 & 8820 & 0.20 & 1.24 & 2.53 \\
\hline 2.11 & Uniform cylinder & 0.20 & 0.1 & 0.75 & 2.22 & 8820 & 0.20 & 1.49 & 1.49 \\
\hline
\end{tabular}

The structures shown in figure 3 were subjected to a range of different flow conditions which are presented in table 1 . The first set of experiments were conducted at a water depth $(\mathrm{h})$ of $0.165 \mathrm{~m}$ at mean flow velocities of $0.20,0.24$ and $0.26 \mathrm{~m} / \mathrm{s}$ with two different types of granular soil of nominal diameters of $0.2 \mathrm{~mm}$ and $0.6 \mathrm{~mm}$. However, the $0.26 \mathrm{~m} / \mathrm{s}$ flow ve- 
locity was not tested against the $0.2 \mathrm{~mm}$ nominal sediment diameter as that would result in scour in the live bed regime. In order to investigate the influence of the water depth on the scour process a second set of experiments were conducted at a smaller depth of $0.1 \mathrm{~m}$ for a mean flow velocity of $0.20 \mathrm{~m} / \mathrm{s}$ for both sediment types mentioned above.

\subsection{Initiation of scour around non-uniform cylindrical structures}

During the initial stages of the scouring process the uniform cylinders showed a different behaviour compared to the conical based structures. For the conical base structures the scour process initiates at the lee of the structure at an angle approximately $120^{\circ}$ relative to flow direction (see figure 4 ). The deepest scour then gradually propagates towards the upstream of the structure and reaches the leading face of the structure and then the deepest scour point stabilizes at a location adjacent to the structure at an angle approximately $45^{\circ}$ relative to the flow direction. This point of initiation of scour agrees with the findings of Tavouktsoglou et al. (2015) who found that the maximum amplification of the bed shear stress occurs at the same location for all conical based structures which also agrees with the observations of Khalfin et al. (1983) who observed that the maximum scour for some conical structures occurred at the lee of the structure. This behaviour is also reported in Petersen (2014) who examined the behavior of edge scour around protected piles with the difference that the maximum scour depth did not move towards the front of the scour protection scheme.

This behaviour can be explained by the presence of the conical base (which is composed of a cone imposed onto a cylinder) which effectively interrupts the formation of the horseshoe vortex at the initial stages of the scour process, thus making it vortex-shedding dominated. Once the scour reaches the leading face of the structure then the horseshoe vortex gains more strength as a results of the greater depth it has to act, therefore making it a horseshoe vortex-dominated process which explains the shift of the maximum depth of scour to the same location where it occurs for a monopile.

\subsection{Temporal evolution of scour}

In figure $5 \mathrm{a}$ the results are shown for the temporal evolution of the non-dimensional maximum scour for each structure type at a mobility ratio of 0.74 and water depth of $0.165 \mathrm{~m}$. The scour depth is nondimensionalised by the equivalent pile diameter as proposed by Coleman (2005) which is a weighted depth averaged structure diameter defined as:
$D_{\text {eq }}=D_{\text {shaft }}\left(\frac{D_{\text {shaft }}}{D_{\text {base }}}\right)\left\{\left(\frac{D_{\text {shaft }}}{D_{\text {base }}}\right)^{3}+0.1-\left[0.47\left(0.75-\frac{Y}{D_{\text {shaft }}}\right)^{0.5}\right]\right\}$

where $\mathrm{Y}$ is the height of the foundation base taken as the height from the bed up to the top of the conical base.

In figure 5-b the same results are nondimensionalised by the diameter of the base. The two figures demonstrate that the different structure types not only yield different rates of scour but also show evidence that the scour rate for certain nonuniform cylindrical structures decelerates and accelerates at different stages as a consequence of the different hydrodynamic responses of the structures. Figure 5a also illustrates that the monopile structure follows the least rapid scour rate from all other surface piercing structures which on physical grounds does not stand, as a uniform cylinder is expected to alter the most the pressure gradient field and thus generate the most scour. This irregularity in interpreting the non-dimensional data of scour can be overcomed by non-dimensionalising scour with the base diameter of the structure which yields a relation with time which has a more intuitive physical meaning.

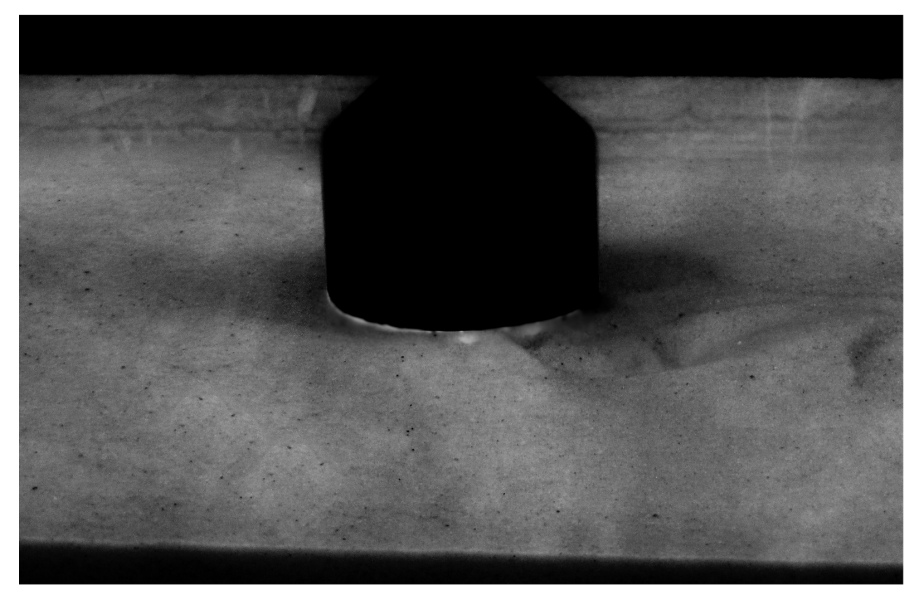

Bed shear stress amplification factor distribution around 45 deg conical bottom (for $0.4 \mathrm{~mm}$ sand

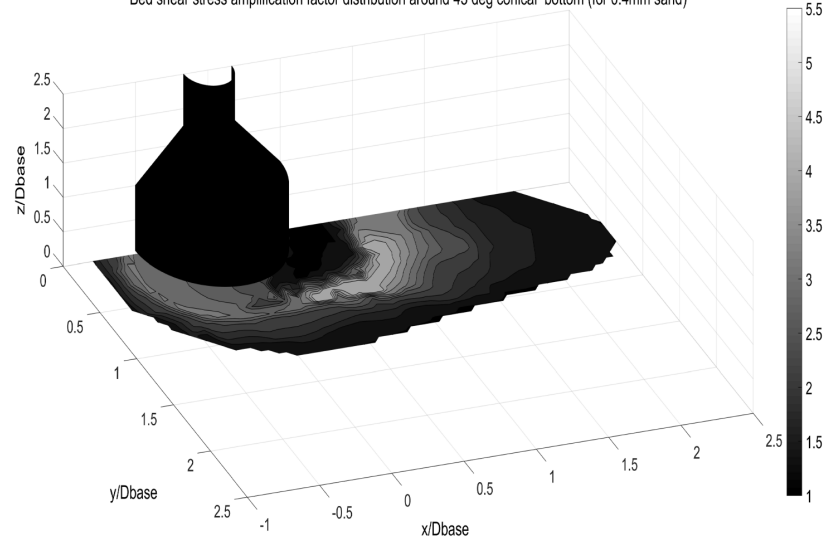

Figure 4: : Initiation of scour at $45^{\circ}$ conical base structure (top), bed shear stress amplification contour map for same structure (bottom); flow direction from left to right. 

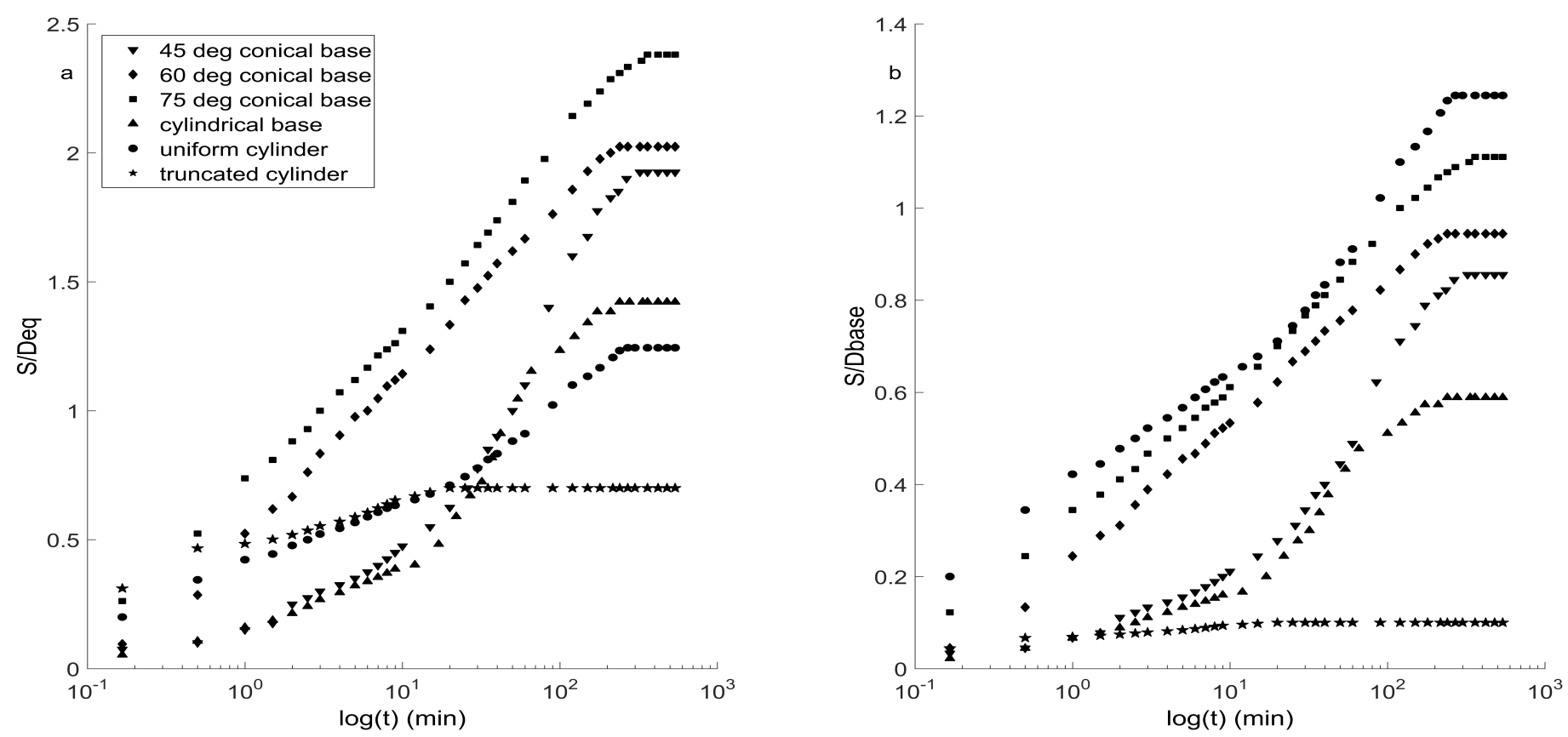

Figure 5: Non-dimensionalisation of scour with base diameter (a - left) and equivalent diameter (b - right)

Figure 6 demonstrates the influence of the ratio $\mathrm{U} / \mathrm{U}_{\mathrm{c}}$ on the scour development for three representative structures tested in this study (cylindrical base, $60^{\circ}$ conical base and uniform cylinder). It can be observed that an increase in the mobility ratio yields an increase in the rate of scour and equilibrium scour depth which is in accordance with the findings of Breusers et al., (1977) for uniform cylinders.

The present data also show that for the cases where $U / U_{c}$ is constant (or has a similar value) an apparent deceleration in the scour rate is observed as it approaches its equilibrium stage for the cases where the coarser bed material is used. This deceleration effect is decreased as the blockage induced by the structure increases and as the mobility ratio increases. It is noted that according to Raudkivi and Ettema (1983) the effects of bed armouring are minimal as the geometric standard deviation of the sediments presented here are minimal since the $\sigma_{\mathrm{g}}$ for the fine sand is 1.1 and for the coarser 1.3.

Figure 6 also shows the effect the side slope of the structure has on the development of scour. It can be observed that as the side slope of a structure increases, the rate of scour also increases which is a result of the local amplification of the pressure gradient due to the increased obstruction.
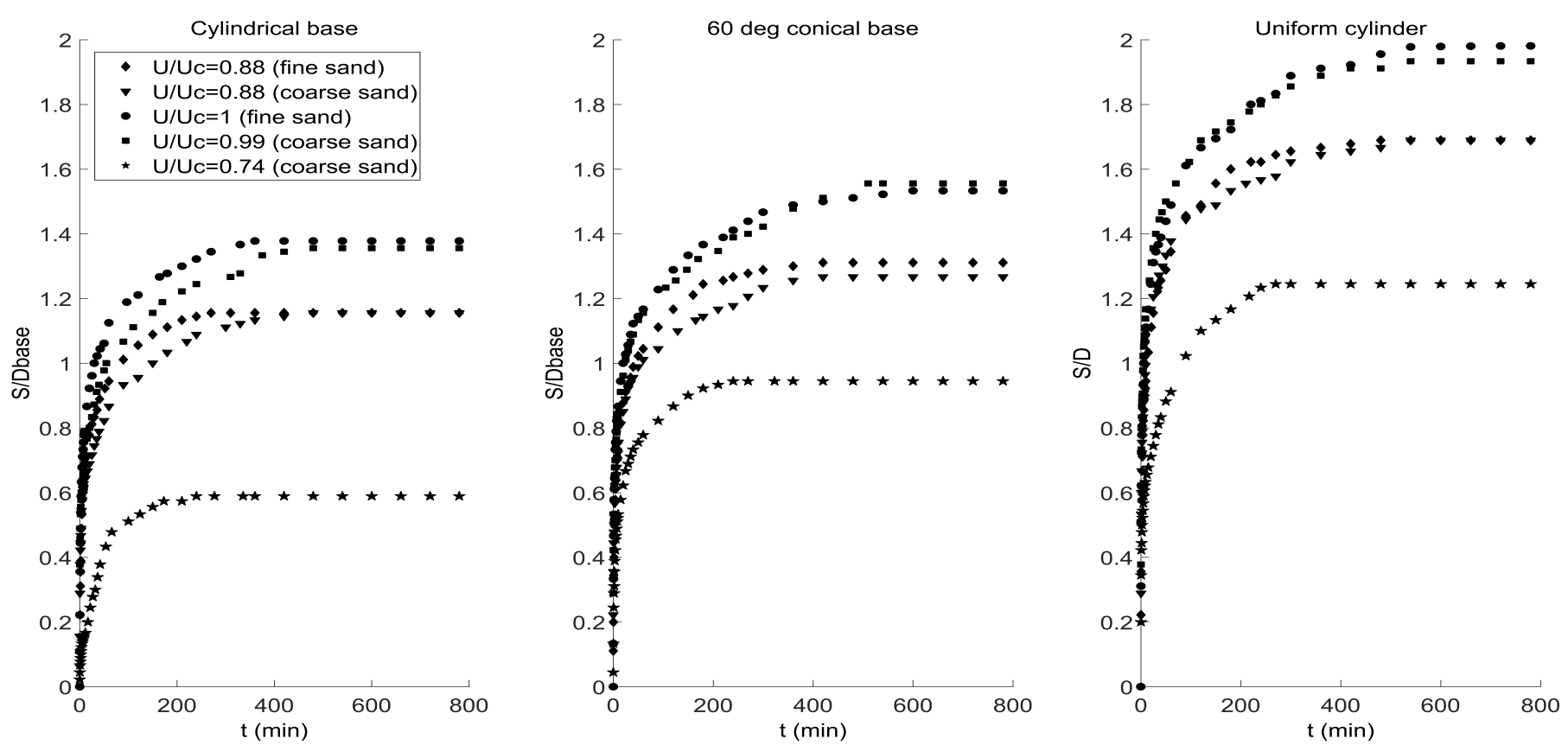

Figure 6: Influence of $U / U_{c}$ on scour development for three different structure geometries. 


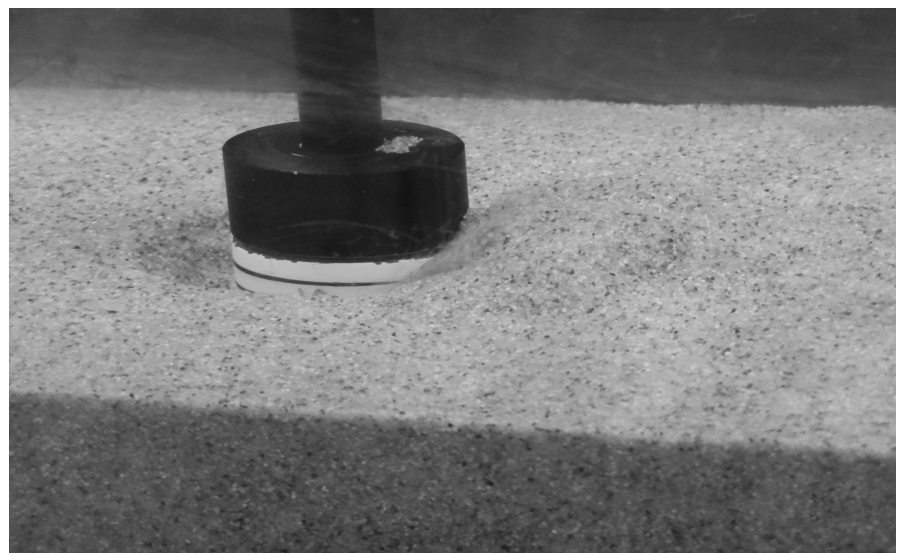

Figure 7: Observed scour depth at cylindrical based pier before undercutting the base cylinder

The present experiments also suggest that the geometry of the foundation plays an important role with regards to the shape of the scour hole. Figure 7 shows that for a cylindrical base structure at low mobility ratios $\left(U / U_{c}<0.8\right)$ the scour hole did not extent around the periphery of the structure. The scour process eroded sediment from the upstream face of the structure and deposited it at the lee. This behaviour has also been reported by Briaud et al. (2004) and Ataie-Ashtiani et al. (2010). Consequently, it can be stated that the shape of the footing plays an important role which should be considered when investigating scour phenomena and particularly scour protection schemes.

\subsection{Equilibrium scour depth}

The results of this study show that the equilibrium scour depth around non-uniform cylindrical geometries is strongly affected by the flow depth. Figure 9 demonstrates this effect for two different flow conditions with a mobility ratio of $0.88-0.90$ (top) and 0.73-0.75 (bottom). Both figures show an increase in the equilibrium scour depth for all non-uniform cylindrical geometries while for the range of conditions tested in this study the uniform cylinders do not seem to be affected by the water depth which agrees with the findings of Melville and Sutherland (1988) for monopiles. The behaviour of both types of structures can be explained in terms of the local change in the pressure gradient as follows:

- In the case of non-uniform cylindrical structures a decreasing flow depth while the mean flow velocity remains constant results in a larger portion of the flow interacting with the wider diameter base of the structure. This translates into an increase in the local pressure field induced by the structure which is responsible for the amplification of the bed shear stress which is the driver of the scour phenomenon. This is clearly indicated in Figure 8 which shows that there is clear correlation between the values of the equilibrium scour depth and the amplification of the bed shear stress as shown in Tavouktsoglou et al, 2015.

- For the uniform cylinder, the effect of a decreasing flow depth is not as apparent as the total flow interacting with the cylinder remains very similar thus not effecting the scour process significantly as long as the water depth is not in the "shallow water scour" regime Guo et al. (2012).

Figure 9 also shows that an increasing side slope of a structure results in deeper equilibrium scour depths. In addition it can be concluded, that for the cylindrical based structures tested in these experiments the equilibrium scour depth is not solely driven by the cylindrical footing. Comparison between the values of equilibrium scour depth of the truncated cylinder and cylindrical based structure show that the latter structure type yields equilibrium scour depths which are $7 \%$ and $36 \%$ greater than that of the truncated cylinder with the same height of emergence, depending on the given flow conditions and sediment type. The data suggest that the difference between the equilibrium scour of the two structures increases as the water depth increases, which is in line with the notion of increased pressure gradients as described in the previous paragraphs. These points suggest that the scouring process is not solely dependent on the horseshoe vortex formed by the footing of the structure, but is also influenced by the shaft of the structure which contributes to the increase of the pressure gradient and therefore increases the equilibrium scour depth.

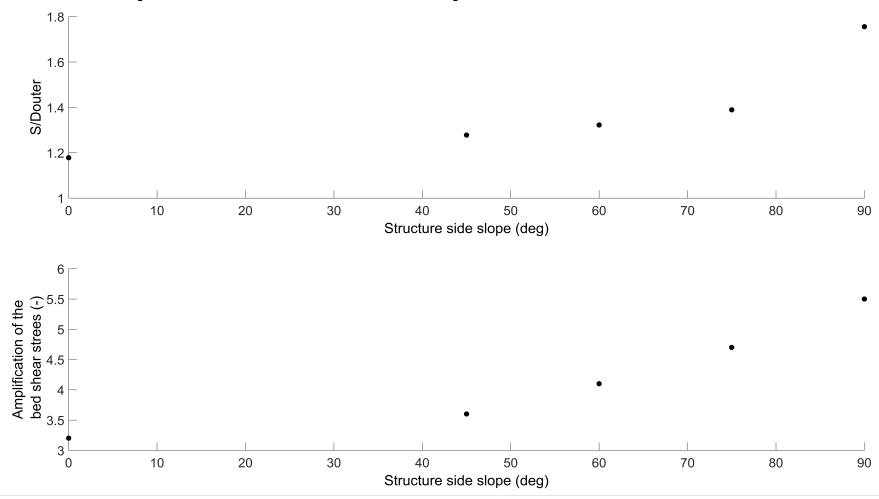

Figure 8: Comparison between results of equilibrium scour from present tests and amplification of the bed shear stress (Source: Tavouktsoglou et al., 2015).

The results also demonstrate that the equivalent diameter is not effective in describing the equilibrium scour depth for the structure geometries tested in this study. Figure 10 shows the same results as in figure 9 with the difference that the scour depths are non-dimensionalised by the equivalent diameter instead of the base diameter. It can be seen that nondimensionalising the equilibrium scour depth with the equivalent diameter yields unrealistically high non-dimensional scour depths in most cases and particularly in the case of submerged/truncated cylinders. 

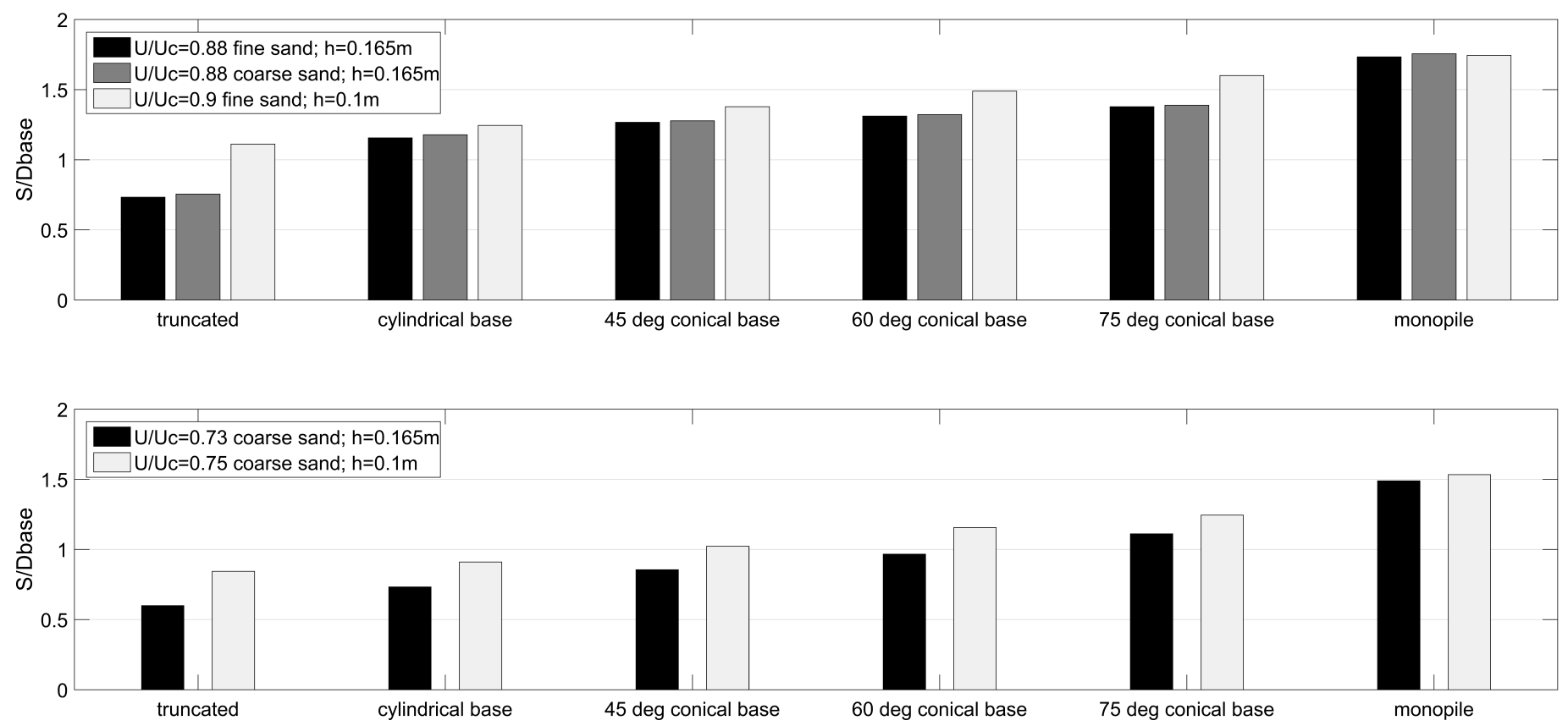

Figure 9: Influence of water depth on equilibrium scour depth for different structure types (non-dimensionalised by base diameter of the structure)
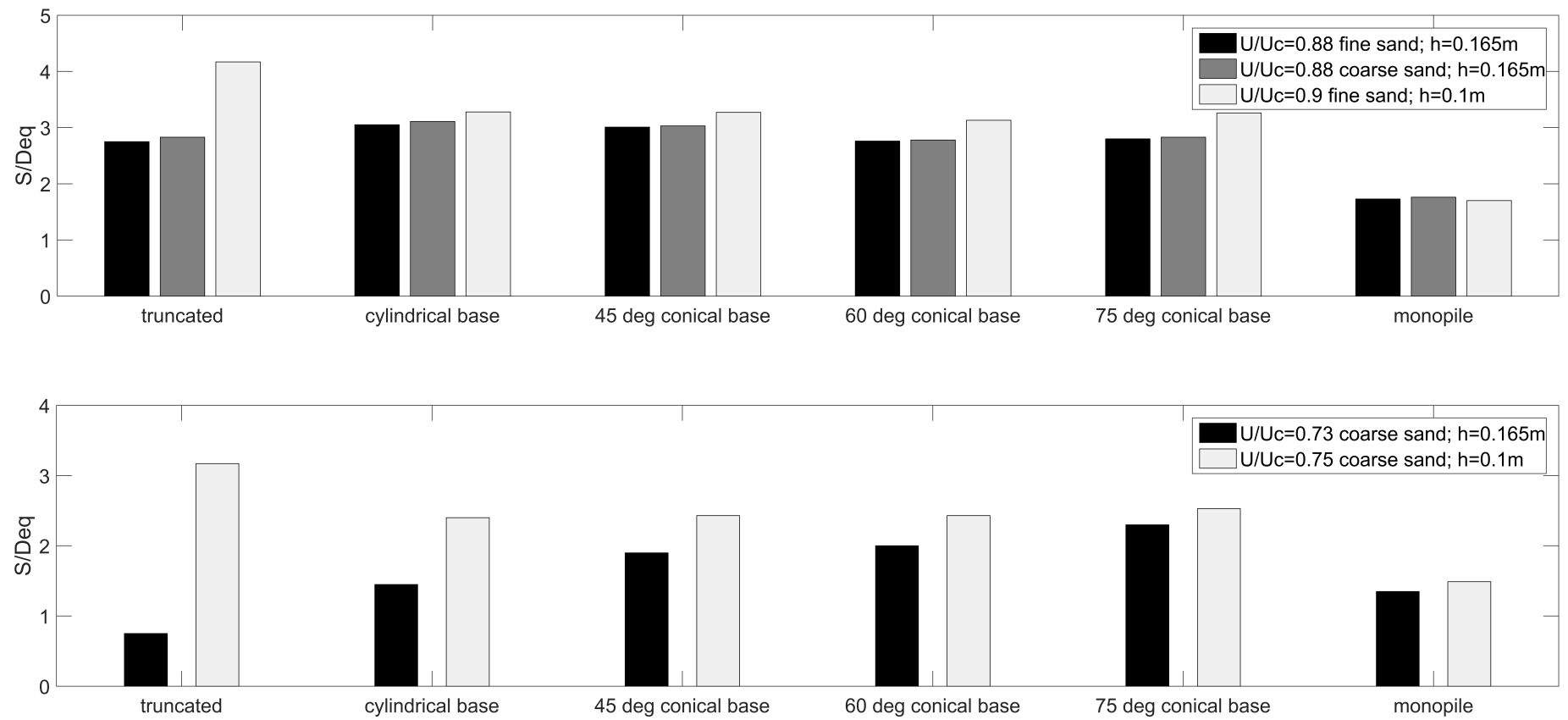

Figure 10: Influence of water depth on equilibrium scour depth for different structure types (non-dimensionalised by equivalent structure diameter)

Given that the scale at which these experiments have been conducted is significantly small, it is expected that the non-dimensional scour depths included in this study may be subject to scale effects associated. According to Schlichting (1979) the size of the boundary layer is proportional to the $1 / \ln (\mathrm{Re})$ which means that the overall turbulence induced by the flow structure interaction would decrease as the Reynolds number increases. In addition Achenbach
(1968) showed that an increasing Re forces the separation point on the face of the structure to shift further to lee of the pile which also would result in a decrease in the sediment transport capacity of the lee wake vortices and thus decrease the overall scour potential. This shows that Re could account for some scale effects that results in smaller scour depths for larger scale structures. Designers should therefore 
account for this effect when incorporating the results included in this study.

\section{CONCLUSIONS}

In this study the influence of non-uniform cylindrical structural geometries on the time development and equilibrium scour depth is examined through a series of small scale experiments. The main findings of the study are summarized below:

- Initiation of scour around conical based structures occurs at an angle $120^{\circ}$ relative to flow direction which differs from that of monopiles which occurs at $45^{\circ}$.

- With regards to the temporal evolution of scour it has been concluded that the nonuniform cylindrical structural geometries should not be translated into a uniform cylinder with an equivalent diameter for two reasons:

i. The individual elements of the structure cause temporal accelerations and/or decelerations which cannot be captured if the structure is considered as an equivalent cylinder.

ii. The equilibrium scour depth and therefore also the time development of scour depth is highly susceptible to changes in water depth which is not the case for uniform cylinders.

iii. The rate of scour is dependent on the side slope of the structure, with steeper side slopes increasing the scour rate and the equilibrium scour depth.

iv. For the same mobility ratio, coarser sediments tend to slow the scour process as it approaches the equilibrium stage. This slowing effect is reduced as the side slope (blockage effect induced) of the structure increases and as the mobility ratio increases.

- Comparison of the data obtained in this study shows a correlation with the amplification of the bed shear stress. This improves the understanding of scour development around non-uniform cylindrical structures.

- The results from these experiments suggest that an increasing side slope of a structure induces greater bed shear stress amplification and thus yield greater equilibrium scour depths.

- Equilibrium scour depth for cylindrical based structures differs from that of truncated cylinders. The difference suggests that the scour process is influenced by the adverse pressure gradient induced by both elements of the structure (footing and shaft) and not only by the footing element.
- Further work is required in order to further understand the influence non-uniform cylindrical structure geometries have on the equilibrium scour depth. Further investigations will focus on examining the influence the pressure gradient induced by the structures have on the equilibrium scour depth in order to create a functional relation which can predict the equilibrium scour depth for these kinds of structures.

\section{REFERENCES}

Achenbach, E. (1968). Distribution of local pressure and skin friction around a circular cylinder in cross-flow up to $\mathrm{Re}=$ 5× 10 6. Journal of Fluid Mechanics, 34(04), 625-639.

Ataie-Ashtiani, B., Baratian-Ghorghi, Z., \& Beheshti, A. A. 2010. Experimental investigation of clear-water local scour of compound piers. Journal of Hydraulic Engineering 136(6): 343-351.

Breusers, H. N. C., Nicollet, G., \& Shen, H. W. 1977. Local scour around cylindrical piers. Journal of Hydraulic Research 15(3): 211-252.

Chabert, J., \& Engeldinger, P. 1956. Study of scour around bridge piers. Rep. Prepared for the Laboratoire National d'Hydraulique.

Chiew, Y. M. 1984. Local scour at bridge piers (Doctoral dissertation,ResearchSpace@Auckland).

Coleman, S. E. 2005. Clearwater local scour at complex piers. Journal of Hydraulic Engineering 131(4): 330-334.

Guo, J., Suaznabar, O., Shan, H., \& Shen, J. 2012. Pier scour in clear-water conditions with non-uniform bed materials (No. FHWA-HRT-12-022).

Jones, J. S., Kilgore, R. T., \& Mistichelli, M. P. 1992. Effects of footing location on bridge pier scour. Journal of Hydraulic Engineering 118(2): 280-290.

Khalfin, I. S. 1983. Local scour around ice-resistant structures caused by wave and current effect. In Proc. The Seventh International Conference on Port and Ocean Engineering under Arctic Conditions, Helsinki, Finland Vol. 2, pp. 9921002.

Melville, B. W., \& Sutherland, A. J. 1988. Design method for local scour at bridge piers. Journal of Hydraulic Engineering 114(10): 1210-1226.

Melville, B. W., \& Raudkivi, A. J. 1996. Effects of foundation geometry on bridge pier scour. Journal of Hydraulic Engineering 122(4): 203-209.

Melville, B. W., \& Chiew, Y. M. 1999. Time scale for local scour at bridge piers. Journal of Hydraulic Engineering 125(1): 59-65.

Moreno, M., Maia, R., \& Couto, L. 2015. Effects of Relative Column Width and Pile-Cap Elevation on Local Scour Depth around Complex Piers. Journal of Hydraulic Engineering 04015051.

Parola, A. C., Mahavadi, S. K., Brown, B. M., \& El Khoury, A. 1996. Effects of rectangular foundation geometry on local pier scour. Journal of Hydraulic Engineering 122(1): 3540.

Petersen, T. 2014. Scour around offshore wind turbine foundations (Doctoral thesis). Technical University of Denmark (DTU), Lyngby, Denmark

Raudkivi, A. J., \& Ettema, R. 1983. Clear-water scour at cylindrical piers. Journal of Hydraulic Engineering 109(3): 338350 . 
Schlichting, H. T., \& Truckenbrodt, E. A. (1979). Aerodynamics of the Airplane. McGraw-Hill Companies.

Sumer, B. M., \& Fredsøe, J. 2002. The mechanics of scour in the marine environment. World Scientific.

Tavouktsoglou, N., Harris, M., Simons, R., \& Whitehouse, R. 2015. Bed Shear Stress Distribution around Offshore Gravity Foundations. In 34th International Conference on Ocean, Offshore and Arctic Engineering, Volume 7: Ocean Engineering. ASME, St. John's, Newfoundland, Canada.

Tsujimoto, T., Murakami, S., Fukushima \& T., Shibata, R. 1987. Local scour around bridge piers and its protection works. Memoirs of the faculty of technology, Kanazawa Univ., Kanazawa, Japan, vol. 20, No. 1, pp. 11-21

Whitehouse, R. 1998. Scour at marine structures: A manual for practical applications. Thomas Telford. 